\title{
KINETIC STUDY OF THE OXIDATIVE DECOLORIZATION OF XYLENOL ORANGE BY HYDROGEN PEROXIDE IN MICELLAR MEDIUM
}

\author{
MOHAMMAD NASIRUDDIN KHAN ${ }^{a^{*}}$, SADAF BHUTTO ${ }^{a}$ \\ ${ }^{a}$ Department of Chemistry, University of Karachi, Karachi-75270, (Pakistan) \\ (Received: March 11, 2009 - Accepted: January 22, 2010)
}

\begin{abstract}
The kinetics of the oxidation of xylenol orange tetrasodium salt by hydrogen peroxide was investigated in the presence of cationic surfactant $(\mathrm{N}$ dodecylpyridinium chloride) \& strongly basic media over the temperature range $20-35{ }^{\circ} \mathrm{C}$. The kinetics studies were carried out as a function of different variables like concentration, $\mathrm{pH}$ and temperature. The described reaction rate is greatly catalyzed by the presence of trace amount of Co(II) ions \& followed pseudosecond- order with respect to dye concentration. Possible mechanism for the catalyzed and uncatalyzed reactions is proposed and found to be coincident with the experimental findings. The derived rate equation is in good agreement with the experimental observations. Thermodynamic parameters were also evaluated.
\end{abstract}

Keywords: Kinetic; Hydrogen peroxide; Xylenol orange; Surfactant; Mechanism

\section{INTRODUCTION}

Hydrogen peroxide has interesting biological properties and environmentally it is a friendly oxidant. It has been used for the oxidation of various organic compounds. [1 -3] Number of works is found in the literature in which hydrogen peroxide has been used as an oxidant for different dyes. [4 - 7] It is one of the principal oxidizing agents used for the treatment of fabrics, paper, cosmetic products and industrial wastewater due to its low cost, simple handling, effectiveness in destroying the chromospheres and being a friendly alternative to chlorine. The oxidation of dyes has got much attraction since last few years. [8- 10] This has been stimulated by environmental, commercial \& social pressures, particularly environmental concerns over residual dyes present in wastewater streams and causing aesthetic pollution. Although, previous studies represent significant steps forward in generating empirical rules governing oxidation, further progress is required in developing the underlying science base.

Xylenol orange [3, 3' bis [N, N' - Di(carboxymethyl)- aminomethyl- O cresolsulphone - phthalein tetrasodium salt] (XO), a heterocyclic species which belongs to the acidic class of dyes. This anionic dye, which is stable and water soluble with an absorption peak at $577 \mathrm{~nm}$, was chosen as a representative species for this study.

A number of papers have been published on the oxidation of xylenol orange (reductive chromogenic agent) by various oxidizing agent. [11 - 13] In previous work, oxidation of xylenol orange was carried out but detailed kinetics study like reaction mechanism, effect of surfactants and thermodynamic parameters were not studied. In proposed work $\mathrm{Co}$ (II) has been used as a catalyst but in previous work other ions were used as catalyst except Co(II) in the oxidation of xylenol orange by bromate.

The oxidation of xylenol orange is a very important redox reaction, as it has an environmental concern. It is a textile dye for industrial uses. Current environmental hazards with these dyes and their derivatives revolve around the carcinogenic potential. Different metal ions like copper (II), iron (II) and (III) etc. have been proved to enhance the decolorization of various dyes. [14, 15] In the present study different metal ions were tried to increase the catalytic rate of the oxidation of XO by hydrogen peroxide, among them $\mathrm{Co}$ (II) has an maximum ability. The effect of $\mathrm{pH}$, temperature, concentration of reagents, foreign ions \& surfactant were also elucidated. To enhance the scope of the present study thermodynamic parameters such as activation energy, enthalpy, entropy etc. were worked out \& possible mechanism for the catalyzed and uncatalyzed reactions is proposed.

\section{EXPERIMENTAL}

\section{Equipment}

Kinetic measurements were performed on a UV-visible spectrophotometer (Shimadzu, Japan $160-\mathrm{A}$ ) at $577 \mathrm{~nm}$. The cell compartment of the spectrophotometer was equipped with a thermostatic controlled bath with a temperature stability of $\pm 0.1^{\circ} \mathrm{C}$. A digital Orion $710 \mathrm{pH}$ meter was used for $\mathrm{pH}$ measurements with an accuracy of \pm 0.001 .

\section{Stock Solution}

All chemicals used were of analytical reagent grade.

Water soluble Xylenol orange 1 ' $10^{-3} \mathrm{M}$ stock was prepared by accurately weighing $0.0766 \mathrm{gm}$ and dissolving in $100 \mathrm{~mL}$ of distilled water. The stock was stable for a week and used to make $0.5^{\prime} 10^{-4} \mathrm{M}$ working solution, diluting by borate buffer $\left(\mathrm{Na}_{2} \mathrm{~B}_{4} \mathrm{O}_{7} \cdot 10 \mathrm{H}_{2} \mathrm{O} \& \mathrm{HCl}\right)$ of $\mathrm{pH} 9.0$.

The working solution of $\mathrm{H}_{2} \mathrm{O}_{2}\left(5^{\prime} 10^{-3} \mathrm{M}\right)$ was prepared immediately before use.

\section{Kinetic Run}

A dry pyrex $10 \mathrm{~mL}$ volumetric flask was used to collect $3 \mathrm{~mL}$ of $\mathrm{H}_{2} \mathrm{O}_{2}$ ( 5 ' $\left.10^{-3} \mathrm{M}\right), 2 \mathrm{~mL}$ of $0.01 \mathrm{M}$ cationic surfactant ( $\mathrm{N}$ - dodecylpyridinium chloride) and an appropriate amount of $\mathrm{Co}(\mathrm{II})$ standard solution. This mixture was kept in a water bath $\left(30^{\circ} \mathrm{C}\right)$ for five minutes. Finally $4.6 \mathrm{~mL}$ solution of xylenol orange tetra sodium salt $\left(0.5^{\prime} 10^{-4} \mathrm{M}\right)$ was added to the same flask and buffer solution of $\mathrm{pH} 9.0$ was added to acquire the predetermined volume. Absorbance of the reaction mixture was measured every 120 seconds at $577 \mathrm{~nm}$ in $1-\mathrm{cm}$ glass cells against a buffer reference.

\section{RESULTS AND DISCUSSION}

\section{Effect of Reaction Monitoring Time}

To select the suitable reaction time, slopes were calculated at every $60 \mathrm{~s}$ from absorbance vs. time curve with $\left[\mathrm{H}_{2} \mathrm{O}_{2}\right]=1.5^{\prime} 10^{-3} \mathrm{~mol} . \mathrm{L}^{-1},[\mathrm{XO}]=2.3^{\prime}$ $10^{-5} \mathrm{~mol} . \mathrm{L}^{-1}$ and $\mathrm{Co}^{+2}=1.2 \times 10^{-5} \mathrm{~mol}$. $\mathrm{L}^{-1}$. The results showed that slope at 120 $\mathrm{s}$ yielded a calibration curve with better correlation coefficient. [16] Therefore, $120 \mathrm{~s}$ was selected with $\mathrm{r}^{2}=0.990$. (Figure 1)

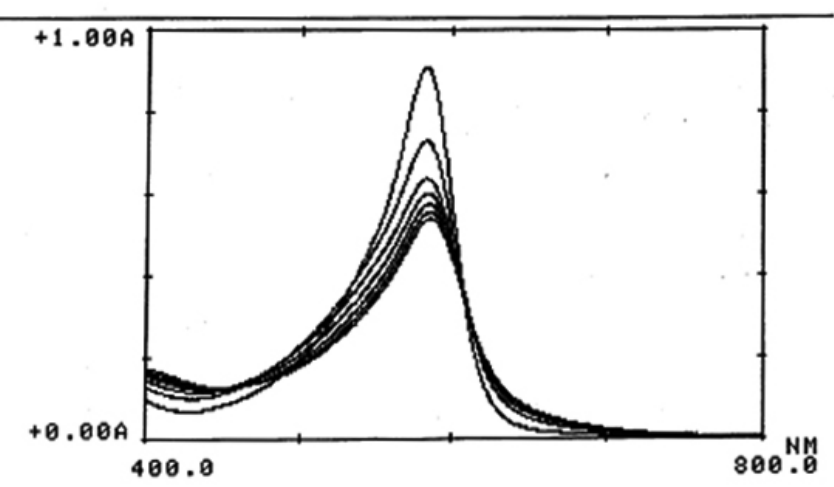

Fig. 1 Variation of the absorbance of xylenol orange tetrasodium salt$\mathrm{H}_{2} \mathrm{O}_{2}$ - cationic surfactant system in the presence $1.2 \times 10^{-5} \mathrm{~mol}^{-\mathrm{L}^{-1}}$ of $\mathrm{Co}(\mathrm{II})$ with time for a $120 \mathrm{~s}$ interval, having $1.5 \times 10^{-3} \mathrm{~mol}^{-1} \mathrm{~L}^{-1}$ of $\mathrm{H}_{2} \mathrm{O}_{2}$ and $2.3 \times 10^{-5}$ mol. $\mathrm{L}^{-1}$ of $\mathrm{XO}$. 


\section{Effect of [Xylenol Orange]}

The influence of concentration of dye (xylenol orange tetra sodium salt) on rate of Co (II) - catalyzed reaction was monitor to optimize the experimental conditions. The reaction was carried out with the concentration range of 1.5 $10^{-5}$ to $3.4^{\prime} 10^{-5} \mathrm{~mol}$. $\mathrm{L}^{-1} \mathrm{XO}$ against $1.5^{\prime} 10^{-3} \mathrm{~mol}^{-1} \mathrm{~L}^{-1} \mathrm{H}_{2} \mathrm{O}_{2}$ and $1.2 \times 10^{-5}$ mol. $\mathrm{L}^{-1} \mathrm{Co}$ (II) at $21^{\circ} \mathrm{C}$. The rate was increased linearly up to $2.6^{\prime} 10^{-5} \mathrm{~mol}$. $\mathrm{L}^{-1}$, whereas a greater concentration of dye had no further increase in the rate, shown in Figure 2. To avoid high absorbance value, $2.3^{\prime} 10^{-5} \mathrm{~mol}^{-\mathrm{L}^{-1}}$ was selected as the optimum concentration of dye.

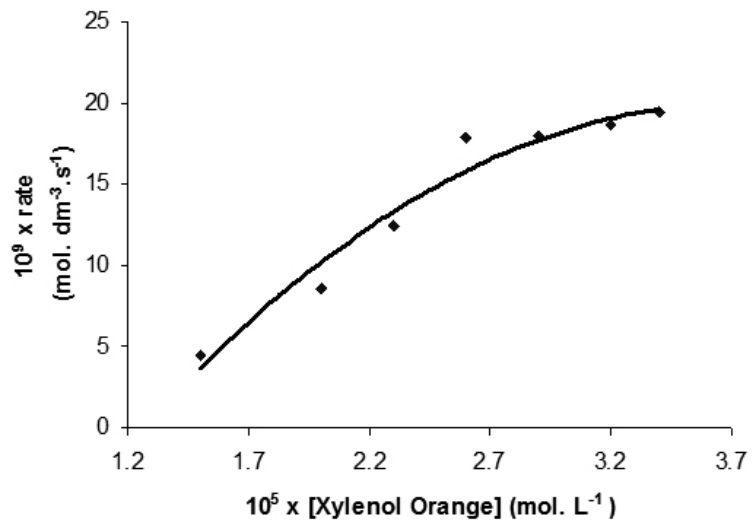

Fig. 2 Effect of [Xylenol Orange] on catalyzed reaction at $21{ }^{\circ} \mathrm{C}$ with $\left[\mathrm{H}_{2} \mathrm{O}_{2}\right]=1.5 \times 10^{-3}$ mol. $\mathrm{L}^{-1} ; \mathrm{pH}=9.00$; concentration of $\mathrm{Co}^{2+}=1.2 \times 10^{-5}$ mol. L ${ }^{-1}$

\section{Effect of pH}

The investigated reaction was studied for $2-10 \mathrm{pH}$ range. It was observed that, proposed reaction proceeded only in alkaline $\mathrm{pH}$. Therefore, the $\mathrm{pH}$ effect of catalyzed and uncatalyzed reaction was studied in the range of 8.00 to 10.00 . At $9.00 \mathrm{pH}$ there was a maximum discrimination between the rate of catalyzed and uncatalyzed reactions (Figure 3). [17] Thus, this $\mathrm{pH}$ was used in the procedure to provide high sensitivity and a low blank reading.

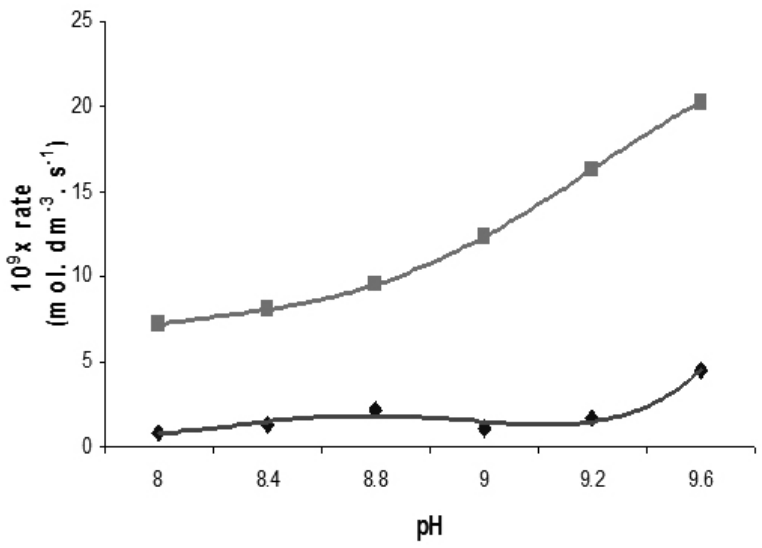

Fig. 3 Effect of $\mathrm{pH}$ on blank and catalyzed reaction at $29^{\circ} \mathrm{C}$

pH range : 8.00 to 9.60 with $1.5 \times 10^{-3}$ mol. $\mathrm{L}^{-1} \mathrm{H}_{2} \mathrm{O}_{2}, 2.30 \times 10^{-5} \mathrm{~mol} . \mathrm{L}^{-1}$ $\mathrm{XO}$ and $1.2 \times 10^{-5} \mathrm{~mol} . \mathrm{L}^{-1} \mathrm{Co}^{2+}$.

$\diamond$ uncatalyzed; $\quad$ catalyzed

\section{Dynamics of Catalyzed Reaction}

With a view to finding good metal catalysts for the title reaction, the effect of a wide range of cations monovalent, divalent and trivalent cations were investigated. $\mathrm{Mg}(\mathrm{II}), \mathrm{Pb}$ (II), $\mathrm{Ce}$ (III), $\mathrm{Hg}$ (II), $\mathrm{Se}$ (IV), $\mathrm{Bi}$ (III), $\mathrm{Zn}$ (II), $\mathrm{Cu}$ (II) have no effect on the reaction rate with $[\mathrm{XO}]=2.3^{\prime} 10^{-5} \mathrm{~mol}^{-\mathrm{L}^{-1}}$ and $\left[\mathrm{H}_{2} \mathrm{O}_{2}\right]=$ $1.5^{\prime} 10^{-3} \mathrm{~mol}$. $\mathrm{L}^{-1}$, whereas, $\mathrm{Fe}$ (II), $\mathrm{Cr}$ (III), $\mathrm{Fe}$ (III) and $\mathrm{Co}$ (II) accelerates the reaction rate with varying catalytic activity. The values of rate were determined for various initial concentration of catalyst [ $\mathrm{Fe}$ (II), $\mathrm{Cr}$ (III), $\mathrm{Fe}$ (III) and $\mathrm{Co}$ (II)]. Cobalt(II) - catalyzed reaction has demonstrated significant catalyzing ability, while $\mathrm{Fe}$ (II), $\mathrm{Cr}$ (III) and $\mathrm{Fe}$ (III) have relatively low catalytic effect, shown in Figure 4.

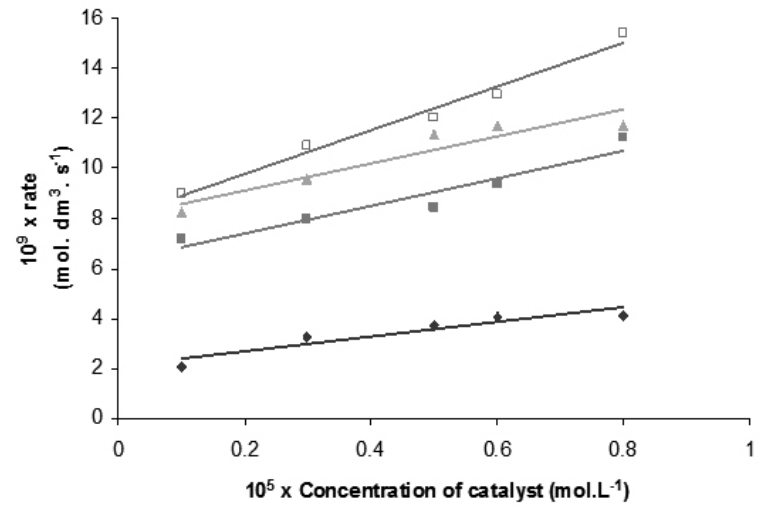

Fig. 4 Effect of concentration of catalyst on reaction at $32{ }^{\circ} \mathrm{C}$ with $1.5 \times 10^{-3}$ mol. $\mathrm{L}^{-1} \mathrm{H}_{2} \mathrm{O}_{2}, 2.30 \times 10^{-5}$ mol.L-1 xylenol orange and $\mathrm{pH}$ 9.00

Catalyst: $\mathrm{Fe}^{2+} ; \quad \square \mathrm{Cr}^{3+} ; \quad \Delta \mathrm{Fe}^{3+} ; \quad \square \mathrm{Co}^{2+}$

Effect of Surfactant

It is well- established that, in many cases, the rate and pathways of all kinds of chemical reactions can be altered by performing the reactions in micellar media instead of pure bulk solvents. [18, 19] Micellar effects on the rate of chemical and biochemical processes can be quite varied, ranging from inhibition to activation [20] of anionic, cationic and non- ionic surfactants. [21 -26] These kinetic effects are generally explained in terms of the partition of the substrate between the aqueous and the micellar phase. Surfactants affect reaction rates by incorporating one or both of the reactants into the micellar aggregates. In order to choose an appropriate micellar system for the reaction, one must take into account the type of charge on the reactants, because the accelerating effect of micelles arises essentially from electrostatic and hydrophobic interactions between the reactants and micellar surface. [27] SDS, Triton X-100 and N-dodecylpyridinium chloride are anionic, non-ionic and cationic surfactants respectively. Xylenol orange is negatively charged specie therefore, it is logical to consider that the cationic micelles could enhance the rate of the said reaction. The enhancement effect of cationic surfactant was observed on Co(II) - catalyzed reaction by the electrostatic interaction of the species involved in the reaction with the positively charged micellar surface. Due to the electrostatic attraction between the positively charged micellar surface and negatively charged XO involved in the reaction are effectively united and hence enhanced the collision frequency and in the result oxidation process became faster. Rate of catalyzed reaction in absence and presence of cationic surfactant was investigated and plots are shown in Figure 5.

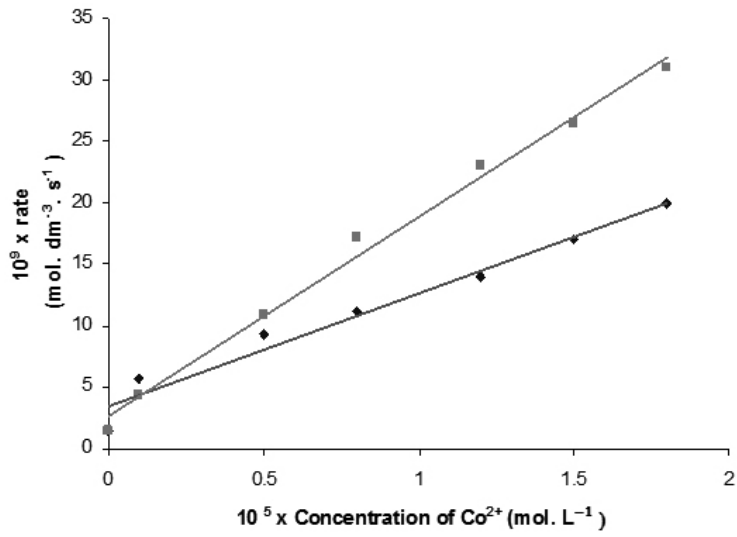

Fig. 5 Calibration curves for $\mathrm{Co}^{2+}$ catalyzed reaction in absence and presence of cationic surfactant at $30{ }^{\circ} \mathrm{C}$ with $1.5 \times 10^{-3} \mathrm{~mol}^{-L^{-1}} \mathrm{H}_{2} \mathrm{O}_{2}, 2.30 \mathrm{x}$ $10^{-5} \mathrm{~mol} . \mathrm{L}^{-1}$ xylenol orange and $\mathrm{pH} 9.00$.

[Cationic surfactant]: $\diamond 0.0 \mathrm{~mol} . \mathrm{L}^{-1} ; \square 2.0 \times 10^{-3} \mathrm{~mol} . \mathrm{L}^{-1}$ 


\section{A Straight Forward Graphical Method for Determining the Order of Reaction}

To determine the order of reaction using integration method, reaction was allowed to cross its half-life under pseudo - order conditions. Integration method is probably the most widely used method of analyzing kinetic data by graphical means. [28] Under the excess concentration condition of hydrogen peroxide, $\left[\mathrm{H}_{2} \mathrm{O}_{2}\right]=1.5^{\prime} 10^{-3} \mathrm{~mol}$. L-1 with $[\mathrm{XO}]=2.3^{\prime} 10^{-5} \mathrm{~mol}$. L-1 ${ }^{-1}$, the plots of time Vs. $\ln (\mathrm{a}-\mathrm{x}), 1 /(\mathrm{a}-\mathrm{x})$ and $1 /(\mathrm{a}-\mathrm{x})^{2}$ were drawn.

Correlation coefficients $\left(\mathrm{r}^{2}\right)$ were obtained by $1^{\text {st }}, 2^{\text {nd }}$ and $3^{\text {rd }}$ order plot. $2^{\text {nd }}$ order plot gave best correlation value 0.998 , reveals that reaction followed $2^{\text {nd }}$ order kinetics with respect to dye concentration as shown in Figure 6. A plot of $k_{\text {obs }}$ vs. varying initial concentration of hydrogen peroxide shows a parallel trend with concentration axis, illustrates zero order behavior.

\section{$2^{\text {nd }}$ order plot}

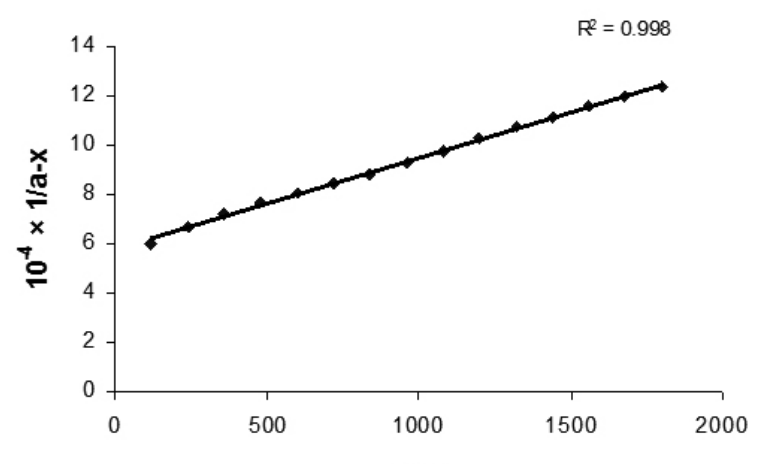

$t(\mathbf{s})$

Fig. 6 Determination of order of reaction

with $1.5 \times 10^{-3} \mathrm{~mol} . \mathrm{L}^{-1} \mathrm{H}_{2} \mathrm{O}_{2}, 2.30 \times 10^{-5} \mathrm{~mol}$. L ${ }^{-1}$ xylenol orange, $3.4 \times 10^{-5}$ $\mathrm{m}$ ol. $\mathrm{L}^{-1}$

$\mathrm{Co}^{2+}$ and $\mathrm{pH} 9.00$

\section{Temperature Effect}

The activation energy for both the uncatalyzed and catalyzed reaction were studied by measuring the rate constants at different temperatures using the Arrhenius equation. Values of other parameters at $26^{\circ} \mathrm{C}$, namely the enthalpy, entropy and Gibb's free energy are calculated \& summarized in Table 1.

It was obvious, that the $\mathrm{Co}(\mathrm{II})$ - catalyzed reaction had a lowest energy of activation of $113.78 \mathrm{~kJ}^{\mathrm{mol}} \mathrm{m}^{-1}$ compared with $184.18,161.66,141.23$ \& $124.74 \mathrm{~kJ} \mathrm{~mol}^{-1}$ for uncatalyzed, $\mathrm{Fe}$ (II) , $\mathrm{Cr}$ (III) and Fe(III) catalyzed reaction respectively.

If the reaction step is bimolecular with two species forming an activated complex resembling a single species, there will be a decrease in entropy on activation. This is called an associative reaction. If reaction is unimolecular and the activated complex resembles an incipient two (or more) species, then an increase in entropy would result. This is termed a dissociative reaction. A reaction some where in between these two extremes is termed interchange, and the entropy is likely to be small. The values of Entropy for the proposed reaction as mentioned in Table 1, are very small and with +ve sign. It interprets that; the proposed reaction may be interchange reaction. [29] $\Delta \mathrm{H}^{\neq}$reflects the effect of bond breaking and bond making in the process of activation. Again a distinction is possible between associative, dissociative and interchange mechanisms. Dissociative reactions have higher $\Delta \mathrm{H}^{\ddagger}$ values than associative mechanisms. Interchange mechanisms, where synchronous bond breaking and bond forming occur, have values in between.

Calculated $\Delta \mathrm{H}^{\ddagger}$ values are large or slight large, reveals that; reaction has interchange mechanism. All the thermodynamic parameters at $26^{\circ} \mathrm{C}$ are in Table 1; show that reaction is endothermic with positive values of $\Delta \mathrm{H}^{\ddagger}$ and $\Delta \mathrm{G}^{\neq}$.
Table 1. Thermodynamic parameters for the oxidation reaction of xylenol orange \& $\mathrm{H}_{2} \mathrm{O}_{2}$

\begin{tabular}{|c|c|c|c|c|}
\hline $\begin{array}{c}\text { Transition } \\
\text { metal ions }\end{array}$ & $\begin{array}{c}\Delta \mathrm{H}^{\neq} / \mathrm{kJ} . \\
\mathrm{mol}^{-1}\end{array}$ & $\begin{array}{c}\Delta \mathrm{S}^{\neq} / \mathrm{kJ} . \\
\mathrm{mol}^{-1} \cdot \mathrm{K}^{-1}\end{array}$ & $\begin{array}{c}\Delta \mathrm{G}^{\neq} / \mathrm{kJ} . \\
\mathrm{mol}^{-1}\end{array}$ & $\begin{array}{c}\mathrm{E} / \mathrm{kJ} . \\
\mathrm{mol}^{-1}\end{array}$ \\
\hline Absent & 181.6 & 0.36 & 73.2 & 184.18 \\
\hline $\mathrm{Fe}^{2+}$ & 159.1 & 0.30 & 70.6 & 161.66 \\
\hline $\mathrm{Cr}^{3+}$ & 138.7 & 0.24 & 66.9 & 141.23 \\
\hline $\mathrm{Fe}^{3+}$ & 122.2 & 0.19 & 66.3 & 124.74 \\
\hline $\mathrm{Co}^{2+}$ & 111.3 & 0.15 & 65.3 & 113.78 \\
\hline
\end{tabular}

\section{Mathematical Basis of Catalytic Method}

Two facts must be considered for to develop mathematical relations valid for catalytic determinations :(i) the uncatalyzed reaction proceeds simultaneously with the catalyzed reaction, and (ii) the rate of the catalyzed reaction is proportional to the concentration of catalyst as a result of the catalytic cycle. [30]

For the reaction

$$
2 R+B \stackrel{c}{\longrightarrow} P+Y
$$

where $R$ and $B$ are reactants ( $R=$ monitored species), $P$ and $Y$ are products, and $c$ is the catalyst, on the basis of the observations obtained by the kinetic runs following general expression can be written:

$$
\begin{aligned}
& -\frac{d[R]}{d t}=k_{u}[R]^{2}+k_{c}[R]^{2}[c]_{0} \\
& -\frac{d[R]}{d t}=[R]^{2}\left(k_{u}+k_{c}[c]_{0}\right)
\end{aligned}
$$

in which $k_{u}=$ the rate coefficient for the uncatalyzed reaction (plus some concentration terms), $k_{c}=$ the rate coefficient for the catalyzed reaction (plus some concentration terms), and $[c]_{0}=$ the initial concentration of catalyst in the system.

Keeping in mind that the catalyzed reaction is much faster than the uncatalyzed one.

For catalytic cycle we can use simplified two - step reaction scheme shown below to develop mathematical relationships between catalytic rate and catalyst concentration

Another important practical requirement needed for successful application is that concentrations of reactants, other than the catalyst and the species whose change in concentration is monitored, must be kept as to make their effect on the rate pseudo-zero- order. The species whose change in concentration is being monitored is adjusted to second- order dependence

$$
\begin{gathered}
2 R+c \underset{k_{-1}}{\stackrel{k_{1}}{\longrightarrow}}(R c)+Y \\
(R c)+B \stackrel{k_{2}}{\longrightarrow} P+c
\end{gathered}
$$

This simplified mechanism for the catalytic cycle leads to two boundary conditions.

\section{Pre-equilibrium condition}

If $k_{1}<<k_{-1}$ and $k_{2}<<k_{1}$, the reaction represented by Eqn 4 becomes rate determining and we have the pre- equilibrium condition in Eqn 3:

$$
[R c]=k \frac{[c][R]^{2}}{[Y]}
$$

where $k=\frac{k_{-1}}{k_{1}}$ equilibrium concentration

quotient for reaction 3 :

The equilibrium concentration of $[c]_{0}$ and $[R]_{0}$ at time $t$ can be defined as

$$
[R]=[R]_{0}-[(R c)]
$$




$$
[c]=[c]_{0}-[(R c)]
$$

In catalytic methods, $[R]_{0} \gg[c]_{0}$ therefore, $[R]$ can be considered equal to $[R]_{0}$ and hence

$$
\begin{aligned}
& {[(R c)]=\frac{k\left([c]_{0}-[(R c)]\right)[R]^{2}}{[Y]}} \\
& {[(R c)]=\frac{k[c]_{0}[R]_{0}^{2}-k[R]_{0}^{2}[(R c)]}{[Y]}} \\
& {[(R c)][Y]=k[c]_{0}[R]_{0}^{2}-k[R]_{0}^{2}[(R c)]} \\
& {[(R c)][Y]=k[c]_{0}[R]_{0}^{2}-k[R]_{0}^{2}[(R c)]} \\
& {[(R c)][Y]+k[R]_{0}^{2}[(R c)]=k[c]_{0}[R]_{0}^{2}} \\
& {[(R c)]\left([Y]+k[R]_{0}^{2}\right)=k[c]_{0}[R]_{0}^{2}} \\
& {[(R c)]=\frac{k[R]_{0}^{2}[c]_{0}}{[Y]+k[R]_{0}^{2}}}
\end{aligned}
$$

In the pre- equilibrium case Eqn 4 is rate limiting and consequently

$$
\begin{aligned}
& \text { rate }=\quad \operatorname{rate}=k_{2}[R c][B] \quad(11) \\
& \text { rate }=\quad \operatorname{rate}=k_{2}[B] \frac{k[R]_{0}^{2}[c]_{0}}{[Y]+k[R]_{0}^{2}}
\end{aligned}
$$

Since measurements were made under conditions for which $[Y]<<k R]_{0}$ (because either $Y$ is not formed at all or, since the catalyst concentration is relatively very low, its concentration is negligible) and $[B]=$ constant, then

$$
\begin{aligned}
& \text { rate }=\frac{d[R]}{d t}=\text { constant } \times[c]_{0} \\
& \text { OR } \\
& \text { rate }=\frac{d[R]}{d t}=k_{2}^{\prime}[c]_{0} \text { (with } k_{2}^{\prime}=\mathrm{k}_{2} \times \text { constant) } \\
& \qquad \mathrm{OR} \\
& \text { rate }=\frac{d[R]}{d t} \propto[c]_{0} \\
& \text { Where } k_{2}^{\prime}=\frac{k k_{2}[B][R]_{0}^{2}}{k[R]_{0}^{2}}
\end{aligned}
$$

This relationship reflects the proportionality between the concentration of catalyst and the rate of the proposed reaction.

Steady - state condition

If $k_{2} \gg k_{1}>k_{-1}$, reaction 3 becomes rate determining, [(Rc)] is small because of the substoichiometric amounts of catalyst, and a steady- state condition develops defined by the approximation

$$
\frac{d[(R c)]}{d t}=0
$$

The rate expression then becomes

$$
\text { rate }=k_{1}[R]^{2}[c]-k_{-1}[(R c)][Y]
$$

Since $[(R c)]$ cannot be measured experimentally, we must resort to the steady state approximation to obtain an expression for it:

$$
\begin{aligned}
& \frac{d[(R c)]}{d t}=0=k_{1}[R]^{2}[c]-k_{-1}[(R c)][Y]-k_{2}[(R c)][B]^{0} \\
& \frac{d[(R c)]}{d t}=0=k_{1}[R]^{2}[c]-k_{-1}[(R c)][Y]-k_{2}[(R c)]
\end{aligned}
$$

substituting the value of $[R]$ as $[R]_{0}$ and $[c]$ as $[c]_{0}-[(R c)]$ (since $R=$ $[R]_{0}-[R c] \cong[R]_{0}$ due to the large concentration of $[\mathrm{R}]_{0}$ as compare to $\left.[R c]\right)$. $0=$

$$
\begin{aligned}
& 0=k_{1}[R]_{0}^{2}\left([c]_{0}-[(R c)]\right)-k_{-1}[(R c)][Y]-k_{2}[(R c)] \\
& k_{1}[R]_{0}^{2}[c]_{0}=[(R c)]\left(k_{1}[R]_{0}^{2}+k_{-1}[Y]+k_{2}\right) \\
& {[(R c)]=\frac{k_{1}[R]_{0}^{2}[c]_{0}}{k_{1}[R]_{0}^{2}+k_{-1}[Y]+k_{2}}}
\end{aligned}
$$

putting the value of $[R c]$ in Eqn 15:

$$
\text { rate }=k_{1}[R]^{2}[c]-k_{-1}[Y] \frac{k_{1}[R]_{0}^{2}[c]_{0}}{k_{1}[R]_{0}^{2}+k_{-1}[Y]+k_{2}}
$$

since $[R]=[R]_{0}$ and $[c]=[c]_{0}-[R c]$ as stated above, we obtain

$$
\begin{aligned}
& \text { rate }=k_{1}[R]_{0}^{2}\left([c]_{0}-[R c]\right)-k_{-1}[Y] \frac{k_{1}[R]_{0}^{2}[c]_{0}}{k_{1}[R]_{0}^{2}+k_{-1}[Y]+k_{2}} \\
& \text { rate }=k_{1}[R]_{0}^{2}[c]_{0}-k_{1}[R]_{0}^{2} \frac{k_{1}[R]_{0}^{2}[c]_{0}}{k_{1}[R]_{0}^{2}+k_{-1}[Y]+k_{2}}-\frac{k_{-1}[Y] k_{1}[R]_{0}^{2}[c]_{0}}{k_{1}[R]_{0}^{2}+k_{-1}[Y]+k_{2}}
\end{aligned}
$$$$
\text { rate }=\frac{k_{1}[R]_{0}^{2}[c]_{0}\left(k_{1}[R]_{0}^{2}+k_{-1}[Y]+k_{2}\right)-k_{1}^{2}[R]_{0}^{4}[c]_{0}-k_{1} k_{-1}[R]_{0}^{2}[c]_{0}[Y]}{k_{1}[R]_{0}^{2}+k_{-1}[Y]+k_{2}}
$$$$
\text { rate }=\frac{k_{1} k_{2}[R]_{0}^{2}[c]_{0}}{k_{1}[R]_{0}^{2} k_{-1}[Y]+k_{2}}
$$

since $\mathrm{k}_{1}[R]^{2} \gg \mathrm{k}_{-1}[Y]$ so it can be neglected

rate $=\frac{k_{1} k_{2}[R]_{0}^{2}[c]_{0}}{k_{1}[R]_{0}^{2}+k_{2}}$

rate $=k_{2}^{\prime}[c]_{0}$

where $k_{2}^{\prime}=\frac{k_{1} k_{2}[R]_{0}^{2}}{k_{1}[R]_{0}^{2}+k_{2}}$

rate $=[c]_{0}$

Both approximations (i.e. for equilibrium and for steady - state) arrive at the same result Eqn 13 and Eqn 18 provide the mathematical relation between catalyst and rate of reaction. The experimental evidence was obtained from different kinetics runs \& illustrated in Figure 4.

Mechanism of Proposed Catalyzed and Uncatalyzed Decolorization Reaction of $\mathrm{XO}$ with $\mathrm{H}_{2} \mathrm{O}_{2}$

The decolorization kinetics of the xylenol orange tetra sodium salt with $\mathrm{H}_{2} \mathrm{O}_{2}$ catalyzed by $\mathrm{Co}^{2+}$ were investigated with the goal of determining a rate expression. The rate of decolorization was measured in a parameterization study, considering the dye, catalyst, the $\mathrm{H}_{2} \mathrm{O}_{2}$ concentration. Initial results demonstrated that alone $\mathrm{H}_{2} \mathrm{O}_{2}$ was not able to decolorize XO. Hydrogen peroxide is necessary for the production of $\mathrm{OH}^{\cdot}$ radicals to initiate the decolorization of $\mathrm{XO}$.

\section{Mechanism : Uncatalyzed Reaction}

Uncatalyzed decolorization of XO with hydrogen peroxide occurs very slowly. Reaction $2 \& 3$ are responsible for the formation of hydroxyl radical. Some of $\mathrm{OH}{ }^{*}$ is used up in the production of $\mathrm{HO}_{2}{ }^{*}$. The hydroperoxyl radicals $\left(\mathrm{HO}_{2}{ }^{\circ}\right)$ generated from reaction 4 and may be utilize for generation of $\mathrm{OH}$ and oxygen. Dimerization of xylenol orange molecules occur in reaction 6 . Reaction 7 to 10 show a consumption \& formation of $\mathrm{OH}$ with intermediates. All steps of uncatalyzed reaction are shown in Table 2. 
Table 2. Scheme of the proposed mechanism for uncatalyzed reaction.

\begin{tabular}{|c|}
\hline Reaction steps \\
\hline 1. $2 \mathrm{H}_{2} \mathrm{O}_{2} \rightarrow 2 \mathrm{H}_{2} \mathrm{O}+\mathrm{O}_{2}$ \\
\hline 2. $\mathrm{H}_{2} \mathrm{O} \rightarrow \mathrm{H}^{+}+\mathrm{OH}^{\cdot}+\bar{e}$ \\
\hline 3. $\mathrm{H}_{2} \mathrm{O}_{2}+\mathrm{H}^{+}+\bar{e} \rightarrow \mathrm{OH}^{\cdot}+\mathrm{H}_{2} \mathrm{O}$ \\
\hline 4. $\mathrm{H}_{2} \mathrm{O}_{2}+\mathrm{OH}^{-} \rightarrow \mathrm{HO}_{2}^{*}+\mathrm{H}_{2} \mathrm{O}$ \\
\hline 5. $\mathrm{H}_{2} \mathrm{O}_{2}+\mathrm{HO}_{2}^{-} \rightarrow \mathrm{OH}^{-}+\mathrm{O}_{2}+\mathrm{H}_{2} \mathrm{O}$ [32] \\
\hline 6. 2Dye $\stackrel{\text { slow }}{\longrightarrow}(\text { Dye) })_{2}^{*} \quad$ (Rate determining step) \\
\hline 7. $(\text { Dye })_{2} *+\mathrm{OH}^{*} \rightarrow \mathrm{P}^{\prime}-\mathrm{OH}$ \\
\hline 8. $\mathrm{H}_{2} \mathrm{O}_{2}+\mathrm{P}^{\prime}-\mathrm{OH}+\rightarrow \mathrm{P}^{\prime \prime}-\mathrm{OH}+2 \mathrm{OH} \cdot$ \\
\hline 9. $2 \mathrm{OH} \cdot \rightarrow \mathrm{H}_{2} \mathrm{O}_{2}$ \\
\hline 10. $\mathrm{OH}^{\cdot}+\mathrm{P}^{\prime \prime}-\mathrm{OH} \rightarrow \mathrm{P}^{\#}-(\mathrm{OH})_{2}$ \\
\hline Overall reaction \\
\hline 11. $2 \mathrm{Dye}+5 \mathrm{H}_{2} \mathrm{O}_{2} \rightarrow \mathrm{P}^{\#}-(\mathrm{OH})_{2}+4 \mathrm{H}_{2} \mathrm{O}+2 \mathrm{O}_{2}$ \\
\hline
\end{tabular}

\section{Mechanism : Catalyzed reaction}

Reaction 1 represents the main pathway of $\mathrm{OH}^{*}$ generation. Immediately after their generation, the hydroxyl radicals initiate nonselective oxidation processes on the surrounding of organic and inorganic species present in the system through mechanisms that include hydrogen abstraction, oxygen addition and radical formation. The rate of $\mathrm{OH}$ generation, $\mathrm{OH}$ specific reactivity towards a target substrate(s) is the other main parameter controlling the efficiency of this process. The nonselective nature of $\mathrm{OH}^{*}$ may create competitive effects. Indeed, $\mathrm{OH} \cdot$ reacts simultaneously with the rest of compounds present in the system, such as generated XO dimerized intermediate. Reactions of hydroxyl radicals with $\mathrm{Co}^{2+}$ reduce both the fraction of $\mathrm{OH}^{*}$ that effectively attack the target compound and the rate of $\mathrm{OH}^{*}$ generation.

Reaction 1 can be described as the generation of $\mathrm{OH}^{*}$ through catalytic decomposition of hydrogen peroxide, carried out by a transition metal. In reaction 1 almost all of the $\mathrm{OH}$ is generated and most of the $\mathrm{Co}^{2+}$ and $\mathrm{H}_{2} \mathrm{O}_{2}$ are consumed. Reaction $2 \& 3$ show $\mathrm{OH}$ s scavenging by $\mathrm{Co}^{2+}$ and $\mathrm{H}_{2} \mathrm{O}_{2}$. The hydroperoxyl radicals $\left(\mathrm{HO}_{2}^{\circ}\right)$ generated from reaction 2 may be transformed to superoxide radical $\left(\mathrm{O}_{2}^{-}{ }^{-}\right)$are linked to the pathways of oxygen generation via reaction with $\mathrm{Co}^{3+}$. Hydroperoxyl is also generated via reaction of $\mathrm{Co}^{3+}$ and $\mathrm{H}_{2} \mathrm{O}_{2}$ as shown in reaction 7. Reaction $6 \& 7$ show that $\mathrm{Co}^{3+}$ is reduced by $\mathrm{O}_{2}$ and $\mathrm{H}_{2} \mathrm{O}_{2}$. In reaction 9 dimer of $\mathrm{XO}$ is formed. On the other hand, reaction 10 to 12 involve $\mathrm{OH}^{*}$ attack on a substrate present in the system (i.e., (Dye) ${ }_{2}^{*}$ and other intermediates). The out come of reaction 10 results in the generation of reactive product $\left(\mathrm{P}^{\prime}-\mathrm{OH}\right)$, which is responsible further two step reactions, like scavenging of $\mathrm{OH}$ reaction 12 . Catalyzed oxidation of $\mathrm{XO}$ by hydrogen peroxide is illustrated in Table 3 .
Table 3. Scheme of the proposed mechanism for catalyzed reaction.

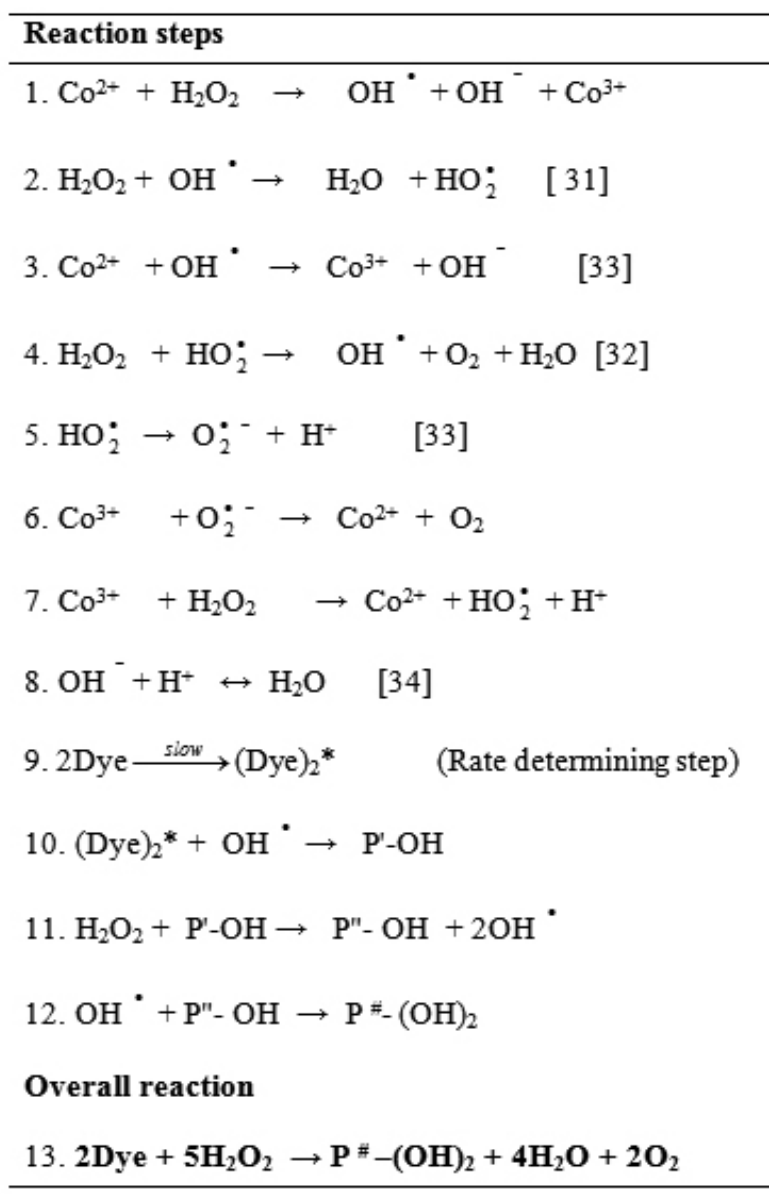

\section{CONCLUSION}

Our results indicate the decolorization rate is pseudo-second order with respect to monitoring specie concentration i.e. dye, represented as " $\mathrm{R}$ " . Rate expression can be written as,

$-\frac{d[R]}{d t}=k[R]^{2}\left[\mathrm{OH}^{\bullet}\right]$

with

$k_{o b s}=k\left[O H^{\bullet}\right]$

where, $\left[\mathrm{OH}^{\circ}\right]$ is in excess therefore, rate expression can be written as,

$-\frac{d[R]}{d t}=k_{o b s}[R]^{2}$

It is concluded that (i) $\mathrm{XO}$ degradation with $\mathrm{Co}^{2+}$ is due exclusively to $\mathrm{OH} \cdot$ attack, and (ii) this process is second order with respect to [XO] and zero order with respect to $\mathrm{H}_{2} \mathrm{O}_{2}$ or its free radical $\left(\mathrm{OH}^{\circ}\right)$.

\section{ACKNOWLEDGEMENT}

The authors are grateful to the Dean, Faculty of Science, University of Karachi, for financial support. 


\section{REFERENCES}

1.- F. A. S. Fabiyi, G. O. Adediran and M. A. Olatunji, Bull. Chem. Soc. Ethiop. 15, 9, (2001).

2.- N. Maeuchihara, S. Nakano and T. Kawashima, Analytical Sciences 17, 255, (2001).

3.- M. K. Beklemishev, A. L. Kapanadze, N. V. Bakhilina and I. F. Dolmanova, Talanta 51, 389, (2000).

4.- H. A. El- Daly, A. F. M. Habib and M. A. Borhan El- Din, Dyes and Pigments 66, 161, (2005).

5.- H. A. El- Daly, A. F. M. Habib and M. A. Borhan El- Din, Dyes and Pigments 57, 197, (2003).

6.- $\quad$ N. Menek, E. Eren and S. Topçu, Dyes and Pigments 68, 205, (2006).

7.- J. Oakes and P. Gratton, J. Chem. Soc., Perkin Trans. 2, 1857, (1998).

8.- G. Absalan and Y. Alipour, Analytical Sciences 19, 635, (2003).

9.- D. X. Cheng and H. W. Zhang, Journal of the Chinese Chemical Society 50, 437, (2003)

10.- N. Pourreza and M. Behpour, Analytical Sciences 14, 997, (1998).

11.- A. A. Ensafi, M. E. Amini and M. Mazloum, Indian J. Chem., Sect. A. Inorg., Bioinorg., Phys., Theor. Anal. Chem. 36 A 626, (1997).

12.- Z. Zhaosheng and Z. Qingmei, Huaxue Shiji 10, 75, (1988).

13.- Z. Zhaosheng and W. Wanhui, Huaxue Shiji 9, 56, (1987).

14.- Z. M. Grahovac, S. S. Mitic and E. T. Pecev, J. Serb. Chem. Soc. 68, 219, (2003).

15.- T. Tomiyasu, N. Yonehara, N. Teshima and T. Kawashima, Analytica Chimica Acta 394, 55, (1999).

16.- A. Safavi, H. R. Sedghy and E. Shams, Fresenius J. Anal. Chem. 365, 504, (1999).

17.- M. E- S. Metwally and Y. El- Shabrawy, Analytical Sciences 16, 633, (2000).
18.- E. H. Cordes Reaction Kinetics in Micelles, Plenum Press, New York., 1973.

19.- J. H. Fendler and E. J. Fendler Catalysis in Micellar and Micromolecular Systems Plenum Press, New York., 1975.

20.- I. V. Berezin, K. Martinek, A. K. Yatsimirski, Rus. Chem. Rev. 42, 787, (1973).

21.- E. P. Bendito and E. Rodenas, Langmuir 7, 232, (1991).

22.- M. N. Khan and Z. Arifin, J. Colloid Interface Sci. 180, 9, (1996).

23.- M. D. Graciani, A. Rodriguez, G. Fernández and M. L. Moya, Langmuir 13, 4239, (1997).

24.- A. Rodriguez, M. D. Graciani and M. L. Moya, J. Colloid Interface Sci. 191, 58, (1997).

25.- A. Dominguez and E. Iglesias, Langmiur 14, 2677, (1998).

26.- A. Malpica, M. Calzadilla and H. Linares, Int. J. Chem. Kin. 30, 273, (1998).

27.- M. L. Lunar, S. Rubio and D. P. Bendito, Anal. Chim. Acta 237, 207, (1990).

28.- K. J. Laidler Chemical Kinetics, Tata Mc Graw-Hill publishing Company Ltd. New Delhi, 1988.

29.- M. R.Wright An Introduction to Chemical Kinetics, John Wiley \& Sons, Ltd., 2004.

30.- H. A. Mottola Kinetic Aspects of Analytical Chemistry, pp. 25, John Wiley \& Sons, Ltd. 1998.

31.- G. V. Buxton, C. L. Greenstock, W. P. Helman and A.B. Ross, J. Phys Chem. Ref. Data 17, 513, (1988).

32.- W. H. Koppenol, J. Butler and J. W. L. Van Leeuwen, Photochem. Photobiol., 28, 655, (1978).

33.- A. A. Burbano, D. D. Dionysiou, M. T. Suidan, T. L. Richardson, Water Research 39, 107, (2005).

34.- A. M. El - Dein, J. A. Libra and U. Wiesmann, Chemosphere 52, 1069, (2003). 